\title{
Foot pain and foot health in an educated population of adults: results from the Glasgow Caledonian University Alumni Foot Health Survey
}

Gordon J. Hendry ${ }^{*}$ (D, Linda Fenocchi, Jim Woodburn and Martijn Steultjens

\begin{abstract}
Background: Foot pain is common amongst the general population and impacts negatively on physical function and quality of life. Associations between personal health characteristics, lifestyle/behaviour factors and foot pain have been studied; however, the role of wider determinants of health on foot pain have received relatively little attention. Objectives of this study are i) to describe foot pain and foot health characteristics in an educated population of adults; ii) to explore associations between moderate-to-severe foot pain and a variety of factors including gender, age, medical conditions/co-morbidity/multi-morbidity, key indicators of general health, foot pathologies, and social determinants of health; and iii) to evaluate associations between moderate-to-severe foot pain and foot function, foot health and health-related quality-of-life.

Methods: Between February and March 2018, Glasgow Caledonian University Alumni with a working email address were invited to participate in the cross-sectional electronic survey (anonymously) by email via the Glasgow Caledonian University Alumni Office. The survey was constructed using the REDCap secure web online survey application and sought information on presence/absence of moderate-to-severe foot pain, patient characteristics (age, body mass index, socioeconomic status, occupation class, comorbidities, and foot pathologies). Prevalence data were expressed as absolute frequencies and percentages. Multivariate logistic and linear regressions were undertaken to identify associations 1) between independent variables and moderate-to-severe foot pain, and 2) between moderate-to-severe foot pain and foot function, foot health and health-related quality of life.

(Continued on next page)
\end{abstract}

\footnotetext{
* Correspondence: gordon.hendry@gcu.ac.uk

School of Health \& Life Sciences, Glasgow Caledonian University,

Cowcaddens Road, Glasgow G4 OBA, Scotland, UK
}

(c) The Author(s). 2018 Open Access This article is distributed under the terms of the Creative Commons Attribution 4.0 International License (http://creativecommons.org/licenses/by/4.0/), which permits unrestricted use, distribution, and reproduction in any medium, provided you give appropriate credit to the original author(s) and the source, provide a link to the Creative Commons license, and indicate if changes were made. The Creative Commons Public Domain Dedication waiver (http://creativecommons.org/publicdomain/zero/1.0/) applies to the data made available in this article, unless otherwise stated. 
(Continued from previous page)

Results: Of 50,228 invitations distributed, there were 7707 unique views and 593 valid completions (median age [inter-quartile range] 42 [31-52], 67.3\% female) of the survey (7.7\% response rate). The sample was comprised predominantly of white Scottish/British (89.4\%) working age adults (95\%), the majority of whom were overweight or obese (57.9\%), and in either full-time or part-time employment (82.5\%) as professionals (72.5\%). Over two-thirds (68. $5 \%$ ) of the sample were classified in the highest 6 deciles (most affluent) of social deprivation. Moderate-to-severe foot pain affected 236/593 respondents (39.8\%). High body mass index, presence of bunions, back pain, rheumatoid arthritis, hip pain and lower occupation class were included in the final multivariate model and all were significantly and independently associated with moderate-to-severe foot pain $(p<0.05)$, except for rheumatoid arthritis $(p=0.057)$. Moderate-to-severe foot pain was significantly and independently associated lower foot function, foot health and health-related quality of life scores following adjustment for age, gender and body mass index $(p<0.05)$.

Conclusions: Moderate-to-severe foot pain was highly prevalent in a university-educated population and was independently associated with female gender, high body mass index, bunions, back pain, hip pain and lower occupational class. Presence of moderate-to-severe foot pain was associated with worse scores for foot function, foot health and health-related quality-of-life. Education attainment does not appear to be protective against moderate-tosevere foot pain.

Keywords: Foot pain, Survey, Foot health, Epidemiology

\section{Background}

Foot pain is reported as common in the general population with prevalence estimates from population surveys ranging from 17 to $30 \%$ [1-4]. Several studies have demonstrated associations between foot pain and various factors including increasing age, female gender, higher body mass index (BMI) [5], foot pathologies, footwear habits [6], other musculoskeletal pain [3, 4], and medical conditions including mental health/depression [7], inflammatory arthritis (RA), osteoarthritis (OA), and heart disease [4]. Importantly, foot pain is associated with impaired foot function, disability and health-related quality-of-life [3, 8, 9], and results in significant healthcare system resource use $[1,10]$. These studies have contributed to a greater understanding of the populations typically affected by foot pain, the impact of foot pain, and the identification of potentially modifiable risk factors which could be targeted by new foot health management strategies.

Associations between personal health characteristics (such as age, gender), lifestyle/behaviour factors (obesity, footwear) and foot pain have been extensively studied [1, 2, $5,6,11]$. However, the role of wider determinants of health on foot pain have received relatively little attention in large-scale epidemiological studies of foot pain [12-14]. Only a few studies have studied associations between foot pain and social determinants of health such as lower socioeconomic class, low occupational class, and lower educational attainment $[12,14-16]$. This is an important gap in current knowledge as people of lower socioeconomic status tend to experience a higher incidence of a variety health problems, multi-morbidity, pain and disability [17], making their conditions more difficult to manage effectively and increasing the burden of treatment receipt $[18,19]$. Indeed, there is strong evidence to suggest that lower socioeconomic status negatively affects treatment outcomes [20], and that treatment burden results in non-adherence and ineffective resource use [21]. Greater understanding of the associations between social determinants of health and foot pain could facilitate the identification of clinically challenging patient groups who may be less likely to respond to contemporary management strategies.

Educational attainment is considered a major social determinant of health which has received relatively little attention in foot pain research. Evidence suggests that more educated individuals generally have fewer comorbidities and are less likely to suffer from long-term diseases, report poor health, and more likely to live longer [22]. This is often termed the education-health gradient [23]. The role of educational attainment in health is complex but it is thought to predict participation in healthy behaviours, avoidance of unhealthy behaviours, less physically demanding occupations and higher income [24]. Education level may be a key correlate of foot pain; whereby lower educational levels may be associated with more severe foot pain. However only a few studies have explored and subsequently demonstrated associations between foot pain and lower educational attainment [14-16, 25]. Therefore, it remains largely unclear as to whether or not educational attainment level plays a protective role against foot pain. Our a priori expectation was that foot pain prevalence would be lower in a university-educated population than the general population. To provide further information, the aims of this study were i) to describe foot pain and foot health characteristics in an educated population of adults; ii) to 
explore associations between moderate-to-severe foot pain and a variety of factors including gender, age, medical conditions/co-morbidity/multi-morbidity, key indicators of general health, foot pathologies, and social determinants of health; and iii) to evaluate associations between moderate-to-severe foot pain and foot function, foot health and health-related quality of life (HRQoL).

\section{Methods}

The Glasgow Caledonian University (GCU) Alumni Foot Health Survey was a cross-sectional, online (web-based), single-event survey designed to explore foot health characteristics and footwear habits amongst a university-educated population of adults. Ethical approval was obtained from the Glasgow Caledonian University, School of Health and Life Sciences Research Ethics Committee (HLS/PSWAHP/ 17/152) on the 12th February 2018. Study data were collected and managed using the Research Electronic Data Capture (REDCap) electronic data capture tool hosted at GCU [26]. REDCap is a secure, web-based application designed to support data capture for research studies, providing an intuitive interface for validated data entry. The survey was open for one month between February and March 2018. No reminders were sent during this period.

\section{Survey administration}

Administration of the survey invitation and single-survey-access web-link was undertaken independently of the study team by the GCU Alumni Office in line with data protection principles. Invitations to participate and the web-link to the online survey were distributed via email using Hobsons Radius ${ }^{\text {TM }}$ Customer Relationship Management software which permits unique views tracking for robust calculation of survey response rates. Invitees were offered a small incentive to participate ( $£ 100$ voucher prize draw entry). The opening page of the survey presented the respondent information sheet and consent form to be completed electronically to allow progression to the start of the main survey content.

\section{Sample selection}

The population of interest was GCU Alumni, defined as individuals who have studied at and graduated from GCU, of which there are approximately 140,000 in total since the university was formed in 1993. GCU is a young university (aged 50 years or younger) [27], with three schools including Engineering and Built Environment (subjects related to engineering; computer, communications and interactive systems; and construction and surveying), Business and Society (subjects related to law, economics, accountancy and risk; business management; social sciences; media and journalism), and Health and Life Sciences (subjects related to nursing and community/public health; psychology, social work and allied health sciences; life sciences). This was a large convenience sample who were selected by nonprobability sampling.

Eligible respondents for the main survey were those who met all of the following criteria: 1) adults (aged 18 and over), 2) registered as an alumnus with the GCU Alumni Office, 3) registered as resident in the United Kingdom, and 4) had provided a working email address for contact. A total of 50,228 (29,984, 59.7\% female) met eligibility criteria and were subsequently sent invitations via email by the GCU Alumni Office.

Based on previous alumni surveys, we estimated that approximately $20 \%$ of the 50,228 invitations to be sent to alumni would be viewed by unique individuals $(n=10,046)$, and that approximately $10 \%$ of those would respond $(n=1005)$. To enable foot pain prevalence in university educated adults (population of 140,000 total alumni) to be estimated with a margin of error not greater than 5\% and confidence limits of a least $95 \%$, a sample size of 384 respondents was required [28, 29].

\section{Research tool and variables}

The web-based anonymous survey and corresponding data dictionary was constructed in REDCap. All responses were by unforced choice. The survey sought demographic and information on respondent characteristics including age (years), gender (male, female, or prefer not to say), employment status (full-time, parttime, voluntary, looking for work, student, looking after home/family, retired, unable to work, other, prefer not to answer), smoking status (smoker, ex-smoker, non-smoker, never smoked, prefer not to say), height and weight, body mass index (BMI) (expressed as a continuous variable and categorical variable for high BMI: $\geq 25$, yes/no) [30]), and ethnicity [31]. Occupation was recorded via free-text entry and allocated to occupation class based on the Standard Occupation Classification 2010 [32] major groups (professional or non-professional occupations). Respondents' post codes were collected in order to calculate indices of social deprivation [33-35]. These were expressed as lowest 4 deciles (most deprived) versus upper 6 deciles (least deprived).

Medical conditions/comorbidities were evaluated using the Self-Administered Comorbidity Questionnaire (SCQ), a valid and reliable questionnaire [36]. This questionnaire is advantageous over other comorbidity scales as it requires no prior medical knowledge and thus is ideal for self-report [36]. Additional information was sought concerning whether respondents currently suffer from hip and/or knee pain, both of 
which have previously been associated with foot pain $[3,37]$.

Self-reported HRQoL was evaluated using the European Quality of Life (Euroqol) EQ-5D-5 L utility index and $100 \mathrm{~mm}$ Health visual analogue scale (VAS) (higher scores indicating better health) [38] respectively; which are both extensively validated and widely adopted tools for measuring HRQoL [38-40]. Self-reported physical activity levels were evaluated using the International Physical Activity Questionnaire Short Form (IPAQ-SF), a highly reliable tool with acceptable criterion validity for measurement of physical activity levels $[41,42]$. The IPAQ-SF inquires about the number of days and the amount of time spent walking, sitting, or participating in moderate and vigorous-intensity activities [41-43] and provides score categories classifying activity levels as low, moderate or high, which were subsequently dichotomised as low versus moderate-to-high physical activity levels.

Current foot pain location (hindfoot, forefoot, toes, ball, arch, heel, nails) was evaluated using a foot pain map (see Fig. 1) previously developed for use in the Framingham Foot Study and frequently adopted in other epidemiological studies of foot pain [3, 44]. Overall foot pain severity was assessed using a $100 \mathrm{~mm}$ foot pain VAS scales (0 no pain, 100 worst pain possible) and then categorised as: absent-mild (0-29) and moderate-to-severe ( $>30$ ) [45]. Recent history of general foot problems experienced over the previous 6 months was assessed using a check-box list of 7 common foot complaints adopted in previous foot pain surveys [4]. Positive responses to the question concerning bunions generated an additional item within

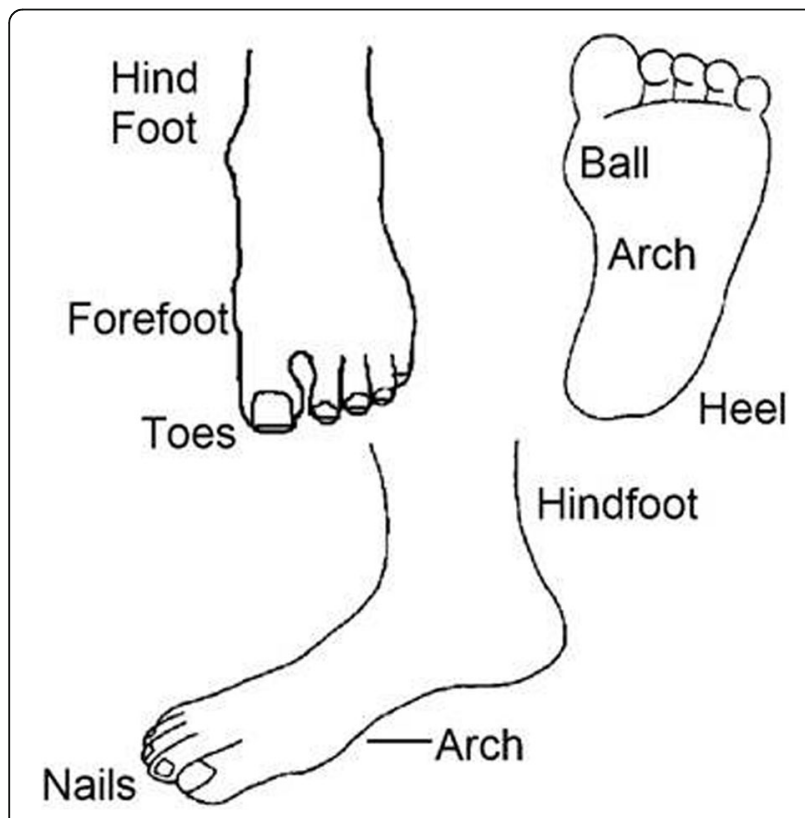

Fig. 1 Foot pain map used for self-report of location of foot pain the survey for self-evaluation of hallux valgus severity (mild, moderate and severe); the Manchester Scale for grading of hallux valgus [4], a valid and reliable tool for self-assessment of presence and severity of hallux valgus [46]. Respondents who indicated that they had bunions from the list of 7 common foot complaints were subsequently presented with the four images from the Manchester Scale representing increasing severity of hallux valgus and were asked to self-assess by selecting the image that looked most like their feet. Foot health was evaluated using the Foot Health Status Questionnaire (FHSQ), a valid and reliable 13-item questionnaire with four domains including pain, function, footwear, and general foot health $[47,48]$.

The survey was pilot tested by six postgraduate students who were independent of the study team and who provided feedback on length, flow, ease of administration, and ease of response [49].

\section{Statistical analyses}

\section{Survey descriptive analyses}

Survey response rates were calculated as a percentage from the total number of unique views of the invitation email after exclusion of invalid responses. Survey data was analysed using descriptive statistics and cross-tabulations, stratified by gender. Where appropriate, continuous data were screened for normality of distributions using the Kolmogorov-Smirnov test. Continuous variables were summarised using medians and inter-quartile ranges (IQR). For categorical data, proportions were calculated and expressed as absolute frequencies (n) and percentages (\%).

\section{Analyses of age, gender and $\mathrm{BMI}$ associations}

To evaluate whether age, gender and BMI were associated with continuous variables related to foot pain, foot health and HRQoL, univariate linear regression analyses were undertaken. Pearson's chi-square or Fisher's exact test statistics with corresponding odds ratios (OR) and 95\% confidence intervals (95\% CIs) were performed to determine the strength of any significant associations between gender and foot pathologies.

\section{Univariate analyses for crude associations with moderate- to-severe foot pain}

To identify categorical variables with crude associations with moderate-to-severe foot pain, Pearson's chi-square or Fisher's exact test statistics with corresponding ORs and 95\% CIs were performed. To evaluate whether age (continuous variable) was associated with moderate-tosevere foot pain, univariate logistic regression analysis was undertaken. Candidate variables with a $p$-value of less than 0.2 were added to the multivariate model. 


\section{Multivariate analyses for independent associations with moderate-to-severe foot pain}

Associations between moderate-to-severe foot pain (dependent variable) and independent variables identified from crude univariate analyses of association were evaluated using backwards stepwise multivariate logistic regression ( $\mathrm{p}$ removal 0.10). Hosmer and Lemeshow tests were used to assess goodness-of-fit. Odd ratios and $95 \%$ confident intervals are reported as measures of strength of independent associations between independent variables and the dependent variable.

\section{Analysis of moderate-to-severe foot pain associations with foot function, health and HRQoL}

To identify associations between foot function, foot health, HRQoL and moderate-to-severe foot pain, multivariate linear regression analyses were undertaken, with age, gender and BMI entered as known covariates [3]. All tests were two-tailed and $p$ values $<0.05$ were considered to indicate statistical significance. All analyses were undertaken using $\mathrm{IBM}^{\odot} \mathrm{SPSS}^{\oplus}$ version 24 .

\section{Results}

Of 50,228 invitations distributed, there were 7707 (15.3\%) unique views; from these there were a total of 757 completions of the survey of which 593 (67.3\% female; $32.4 \%$ male; $0.3 \%$ preferred not to say) were valid, giving an overall response rate of $7.7 \%$. There was a higher proportion of women $(67.3 \% \mathrm{v} 59.7 \%)$ and lower proportion of men $(32.4 \% \mathrm{v} 40.3 \%)$ amongst responders relative to non-responders respectively. No other information was available for non-responders.

Respondent demographic characteristics are summarised in Table 1. The sample population was comprised predominantly of white Scottish/British (89.4\%) working age adults (95\%), the majority of whom were overweight or obese $(57.9 \%)$, and in either full-time or part-time employment (82.5\%) as professionals (72.5\%). The distribution of age was non-normal, positively skewed, and approximately multimodal for ages 23, 32 and 44 years. Over two-thirds (68.5\%) of the sample were classified in the highest 6 deciles (most affluent) of social deprivation.

Foot pain ( $>0 / 100 \mathrm{~mm}$ on foot pain VAS scales) experienced in the previous week was common, affecting $331 / 593(74 \%)$ of respondents and was typically in the mild category $(<30 / 100 \mathrm{~mm})$. Overall, respondents typically reported sub-optimal foot health for FHSQ subscales relating to pain, general foot health and footwear, but better (near normal) foot function (Table 2).

Female gender was significantly associated with more severe foot pain, worse FHSQ scores for foot pain, foot function, general foot health and footwear subscales (all $p<0.05$ ). HRQoL scores were similar for women and men are indicative of suboptimal health states. Age was not associated with foot pain (Fig. 2) or foot function, but was significantly associated with general foot health, footwear-related foot health, and HRQoL (all $p<0.05$ ). Higher BMI was significantly associated with poorer foot pain, function, general foot health, footwear-related foot health and HRQoL scores (all $p<0.001$ ).

Moderate-to-severe foot pain experienced in the previous week affected 236/593 (prevalence [95\% CI] of $39.8 \%$, [35.9-43.7\%]). The presence of moderate-to-severe foot pain was not associated with increasing age (OR 1.00, 95\% CI 0.99-1.01, $p=0.98$ ) or social deprivation (OR 0.86 , 95\% CI $0.57-1.29, p=0.46$ ), but was associated with non-professional occupation class at the $p<0.2$ level (OR 1.45, 95\% CI 0.99-2.01, $p=0.05$ ). Most commonly reported regional sites for pain in the foot were the arch (26.3\%), the ball of the foot $(24.6 \%)$, toes $(20.7 \%)$, forefoot $(20.1 \%)$ and the heel (18.5\%) (Table 3). Female gender was associated with foot pain affecting the forefoot, ball of the foot, and heel regions (all $p<0.05$ ) (Table 4).

Callus and nail problems in the previous 6 months were highly prevalent (Table 5). Female gender was associated with greater prevalence of callous, corns and bunions, and lower prevalence of fungal foot infections (all $p<0.05$ ). Respondents that reported having bunions $(n=75)$ subsequently self-assessed these for hallux valgus severity as absent $(n=3)$, mild $(n=27)$, moderate $(n=38)$ and severe $(n=7)$. The presence of bunions was associated with moderate-to-severe foot pain $(p<0.05)$, while the presence of claw toes, and nail problems were associated with moderate-to-severe foot pain at the $p<0.2$ level.

In terms of general health, the majority of respondents reported at least 1 medical condition (55.1\%) and approximately one-quarter reported at least 2 medical conditions (multi-morbidity) (26.9\%) (Table 6). Threehundred-and-sixteen (56\%) were classed as either overweight or obese despite relatively low proportions being classed as physically inactive. Only 5.5\% of respondents were current smokers. Most frequently reported medical conditions/comorbidities were back pain (26.3\%), knee pain $(23.1 \%)$, hip pain $(11.8 \%)$, depression $(11.2 \%)$, and high blood pressure (BP) (9.8\%) (Table 6); which were all more prevalent amongst female respondents except for high BP. SCQ comorbidity scores were similar for women and men.

Medical conditions back pain, knee pain, hip pain, high BP, rheumatoid arthritis, being overweight/obese (see Fig. 3) and having either any one medical condition or multi-morbidity were all associated with moderate-to-severe foot pain $(p<0.05)$. Ulcer/stomach disease, 
Table 1 Demographics

\begin{tabular}{|c|c|c|c|}
\hline & $\begin{array}{l}\text { Women } \\
(n=399)\end{array}$ & $\begin{array}{l}\text { Men } \\
(n=192)\end{array}$ & $\begin{array}{l}\text { Total } \\
(n=593) f\end{array}$ \\
\hline$\overline{\text { Age, median }(\mathrm{IQR})^{a}}$ & $42(31-52)$ & $42(32-52)$ & $42(31-52)$ \\
\hline BMI, median (IQR) ${ }^{b}$ & $25.2(22.7-29.6)$ & $26.8(24.0-30.7)$ & $25.8(23.0-29.9)$ \\
\hline Social deprivation (lowest 4 deciles), $\mathrm{n}(\%)^{\mathrm{c}}$ & $111(30.4)$ & $57(33.5)$ & $169(31.5)$ \\
\hline Professional occupation, n (\%) & $281(72.6)$ & $135(72.6)$ & $416(72.5)$ \\
\hline \multicolumn{4}{|l|}{ Employment $^{d}$} \\
\hline Paid/self-employed, n (\%) & $253(63.9)$ & $137(72.1)$ & $391(66.5)$ \\
\hline Paid/self-employed, part-time, n (\%) & $78(19.7)$ & $16(8.4)$ & $94(16.0)$ \\
\hline Voluntary work, n (\%) & $3(0.8)$ & $5(2.6)$ & $8(1.4)$ \\
\hline Looking for work, n (\%) & $10(2.5)$ & $8(4.2)$ & $18(3.1)$ \\
\hline Student, n (\%) & $5(1.3)$ & $8(4.2)$ & $13(2.2)$ \\
\hline Looking after the home/family, n (\%) & $3(0.8)$ & $1(0.5)$ & $4(0.7)$ \\
\hline Wholly retired, $\mathrm{n}(\%)$ & $32(8.1)$ & $12(6.3)$ & $44(7.5)$ \\
\hline Permanently unable to work, $\mathrm{n}(\%)$ & $2(0.5)$ & 0 & $2(0.3)$ \\
\hline Other, n (\%) & $9(2.3)$ & $1(0.5)$ & $10(1.7)$ \\
\hline Prefer not to answer, n (\%) & $1(0.3)$ & $2(1.1)$ & $4(0.7)$ \\
\hline Current smoker, $\mathrm{n}(\%)^{\mathrm{e}}$ & $19(4.8)$ & $13(6.8)$ & $32(5.5)$ \\
\hline \multicolumn{4}{|l|}{ Ethnicity } \\
\hline White Scottish n (\%) & $312(78.2)$ & $147(76.6)$ & $460(77.6)$ \\
\hline White other British, n (\%) & $48(12.0)$ & $22(11.5)$ & $70(11.8)$ \\
\hline White Irish, n (\%) & $4(1.0)$ & $3(1.6)$ & $7(1.2)$ \\
\hline White Polish, n (\%) & $5(1.3)$ & $1(0.5)$ & $6(1.0)$ \\
\hline Any other white ethnic group, n (\%) & $9(2.3)$ & $6(3.1)$ & $15(2.5)$ \\
\hline Any multiple ethnic groups, n (\%) & $7(1.8)$ & $1(0.5)$ & $8(1.3)$ \\
\hline Pakistani, Pakistani Scottish/British, n (\%) & $2(0.5)$ & $2(1.0)$ & $4(0.7)$ \\
\hline Indian, Indian Scottish/British, n (\%) & 0 & $4(2.1)$ & $6(1.0)$ \\
\hline Chinese, Chinese Scottish/British, n (\%) & $3(0.8)$ & $1(0.5)$ & $4(0.7)$ \\
\hline Any other Asian ethnic group, n (\%) & $2(0.5)$ & 0 & $2(0.3)$ \\
\hline African, African Scottish/British, n (\%) & $1(0.3)$ & $3(1.6)$ & $4(0.7)$ \\
\hline Carribean, Carribean Scottish/British, n (\%) & 0 & $1(0.5)$ & $1(0.2)$ \\
\hline Arab, Arab Scottish/British, n (\%) & $1(0.3)$ & $1(0.5)$ & $2(0.3)$ \\
\hline Any other ethnic group, n (\%) & $1(0.3)$ & 0 & $1(0.2)$ \\
\hline Prefer not to say, n (\%) & $1(0.3)$ & 0 & $2(0.3)$ \\
\hline
\end{tabular}

age $\mathrm{n}(\%)$ overall, female, male missing values: 15 (2.5); 12 (3.1); 3 (1.6)

${ }^{b}$ BMI $n$ (\%) overall, female, male missing values: 47 (7.9); 33 (8.3); 13 (6.8)

'Soc dep n (\%) overall, female, male missing values: 56 (9.4); 34 (8.8); 22(11.6)

${ }^{d}$ Employment status $\mathrm{n}(\%)$ overall, female, male missing values: 5 (0.84); 3 (0.78); 2 (1.1)

${ }^{\text {e}}$ Smoking status $\mathrm{n}(\%)$ overall, female, male missing values: 8 (1.3); 6 (1.6); 2 (1.1)

fincludes 2 cases who preferred not to disclose gender

depression, OA and 'other' comorbidities were associated with moderate-to-severe foot pain at the $p<0.2$ level.

Following univariate analyses, categorical variables gender, and presence/absence of bunions, claw toes, nail problems, high BP, ulcer/stomach disease, depression, OA, back pain, RA, hip pain, knee pain, one or more medical conditions (comorbidity), high BMI (>25), and occupation class (non-professional) were included in the stepwise multivariate model. High BMI, bunions, back pain, RA, hip pain and occupation class were included in the final model (Table 7) and all were significantly and independently associated with moderate-to-severe foot pain $(p<0.05)$ except for RA $(p=0.057)$. This model was a statistically adequate fit to the observed data (Hosmer and Lemeshow $p=0.366$ ). 
Table 2 Foot pain, foot health, HRQoL characteristics and gender associations

\begin{tabular}{|c|c|c|c|c|}
\hline & Women $(n=399)$ & Men $(n=192)$ & Total $(n=593)^{d}$ & Standardised Beta \\
\hline \multicolumn{5}{|c|}{ Foot pain severity (past week) 100 mm VAS scales } \\
\hline Left foot, median (IQR) & $10(0-45)$ & $8.5(0-31.8)$ & $10.0(0-38.5)$ & 0.08 \\
\hline Right foot, median (IQR) & $14(1-50)$ & $4(0-34.8)$ & $11.0(0-41.0)$ & 0.08 \\
\hline Overall, median (IQR) & $20(3-53)$ & $13(0-47.3)$ & $17.0(2-52.0)$ & $0.09^{*}$ \\
\hline \multicolumn{5}{|l|}{ Foot Health: FHSQ } \\
\hline Pain, median (IQR) & $72.5(53.8-84.4)$ & $81.3(65.6-87.5)$ & $78.1(59.4-84.4)$ & $-0.19^{*}$ \\
\hline Function, median (IQR) & $93.8(81.3-100.0)$ & $100(87.5-100.0)$ & $93.8(81.3-100.0)$ & $-0.09^{*}$ \\
\hline General foot health, median (IQR) & $60.0(42.5-85.0)$ & $72.5(60.0-85.0)$ & $60.0(42.5-85.0)$ & $-0.11^{*}$ \\
\hline Footwear, median (IQR) & $50.0(25.0-75.0)$ & $75.0(41.7-100.0)$ & $58.3(33.3-83.3)$ & $-0.24^{*}$ \\
\hline \multicolumn{5}{|l|}{ HRQoL: EQ. 5D-5 L } \\
\hline EQ 5D-5 L Index', median (IQR) & $0.837(0.735-0.879)$ & $0.837(0.767-1.0)$ & $0.837(0.740-1.00)$ & -0.05 \\
\hline EQ 5D-5 L VAS', median (IQR) & $82(70-90)$ & $80(66-90)$ & $80(70-90)$ & 0.07 \\
\hline
\end{tabular}

${ }^{a}$ female $=376 ; n$ male $=181 ; n$ total 559

${ }^{b} \mathrm{n}$ female $=350 ; \mathrm{n}$ male $=168 ; \mathrm{n}$ total 520

$c_{n}$ female $=342 ; n$ male $=163 ; n$ total 506

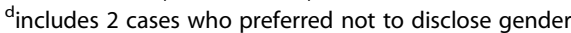

*univariate linear regression female gender association significant at $p<0.05$

Respondents with moderate-to-severe foot pain had significantly worse scores for foot function, foot health and HRQoL compared to those without (Table 8).

\section{Discussion}

Despite recruiting a large sample size which met the minimum target required for estimation of foot pain prevalence, this survey achieved a response rate of $7.7 \%$ which was lower than a priori expectations. Little information was available to permit robust responder versus non-responder comparisons; however, for available data, a difference was observed for gender with proportionally more women amongst responders relative to non-responders. While cautious interpretation is warranted due to potential non-response bias, tentatively these findings may be generalizable to other university educated populations who graduated from young universities offering similar prospectuses, with similar student demographic profiles. The true size of the target population is unknown; however, Labour Force Survey

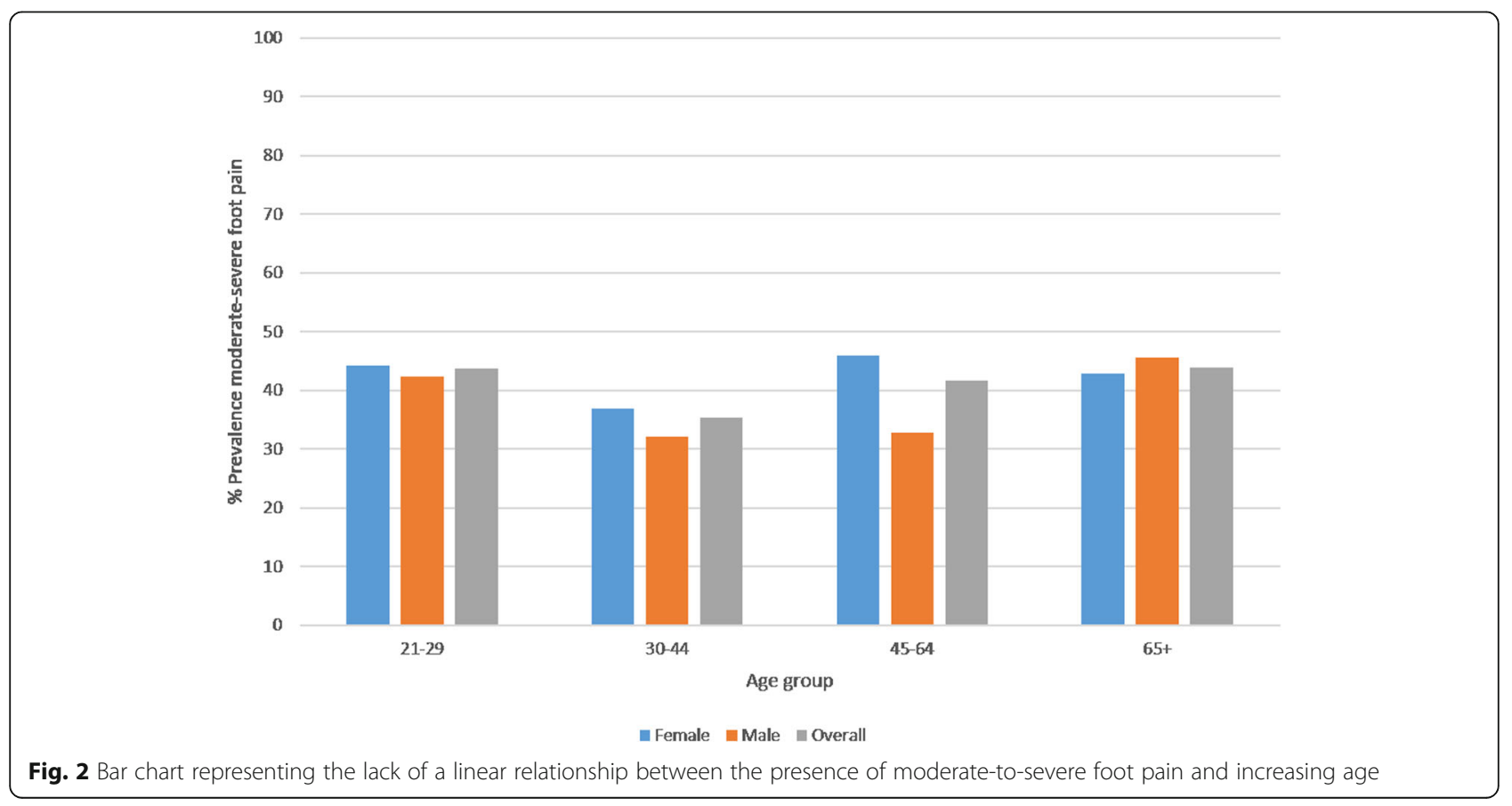


Table 3 Foot pain, foot health, HRQoL associations with age and $\mathrm{BMI}$

\begin{tabular}{|c|c|c|}
\hline & Standardised beta & $p$-value \\
\hline \multicolumn{3}{|c|}{$\begin{array}{l}\text { Foot pain severity } \\
\text { (past week) } 100 \mathrm{~mm} \\
\text { VAS scales }\end{array}$} \\
\hline $\operatorname{Age}^{\mathrm{a}}$ & 0.04 & 0.316 \\
\hline $\mathrm{BMI}^{\mathrm{b}}$ & 0.20 & $<0.001^{*}$ \\
\hline \multicolumn{3}{|c|}{ FHSQ Pain } \\
\hline $\mathrm{Age}^{\mathrm{c}}$ & -0.08 & 0.051 \\
\hline$B M I^{d}$ & -0.22 & $<0.001^{*}$ \\
\hline \multicolumn{3}{|c|}{ FHSQ Function } \\
\hline $\mathrm{Age}^{\mathrm{c}}$ & -0.03 & 0.448 \\
\hline$B M I^{d}$ & -0.29 & $<0.001^{*}$ \\
\hline \multicolumn{3}{|c|}{$\begin{array}{l}\text { FHSQ General } \\
\text { foot health }\end{array}$} \\
\hline $\mathrm{Age}^{\mathrm{c}}$ & -0.13 & $0.002^{*}$ \\
\hline $\mathrm{BMI}^{\mathrm{d}}$ & -0.25 & $<0.001^{*}$ \\
\hline \multicolumn{3}{|c|}{ FHSQ Footwear } \\
\hline $\mathrm{Age}^{\mathrm{c}}$ & -0.09 & $0.040 *$ \\
\hline $\mathrm{BMI}^{\mathrm{d}}$ & -0.17 & $<0.001^{*}$ \\
\hline \multicolumn{3}{|c|}{$\begin{array}{l}\text { EQ 5D-5 L Index } \\
\text { median (IQR) }\end{array}$} \\
\hline $\mathrm{Age}^{\mathrm{e}}$ & -0.10 & $0.025^{*}$ \\
\hline $\mathrm{BMI}^{\mathrm{f}}$ & -0.29 & $<0.001^{*}$ \\
\hline \multicolumn{3}{|c|}{$\begin{array}{l}\text { EQ 5D-5 L VASc, } \\
\text { median (IQR) }\end{array}$} \\
\hline $\operatorname{Age}^{g}$ & 0.09 & $0.034 *$ \\
\hline$B M I^{h}$ & -0.26 & $<0.001^{*}$ \\
\hline $\begin{array}{l}{ }^{\mathrm{a}_{n}}=578 \\
\mathrm{~b}_{n}=546 \\
{ }^{c_{n}}=544 \\
{ }^{d_{n}}=516 \\
{ }^{\mathrm{e}_{n}}=508 \\
{ }^{\mathrm{f}} n=483 \\
{ }^{\mathrm{g}} n=493 \\
{ }^{\mathrm{h}} n=470 \\
{ }^{*} \text { Multiple }\end{array}$ & 0.05 & \\
\hline
\end{tabular}

data suggests that $42 \%$ of the United Kingdom (UK) population aged 21 to 64 in 2017 had achieved higher education qualifications [50].

The results of this survey demonstrate that moderateto-severe foot pain was highly prevalent in a university educated population of adults, affecting approximately $40 \%$ of respondents, and was associated with poorer foot health and reduced HRQoL. While definitions vary, the prevalence of foot pain reported in this study is significantly higher than estimates reported in population surveys $[1,2,4]$. This could be explained in part by the general health characteristics of the respondents amongst whom there was high prevalence of obesity, comorbidity, and multi-morbidity. Previous studies have identified that both risk factors and pathogenic links between musculoskeletal disorders and other medical conditions often result in development multi-morbidity; for example, obesity is a known risk factor for both OA and diabetes [51]. While the general health characteristics were typically poor given the age range of the sample, it is possible that the high foot pain prevalence estimates were vulnerable to non-response bias, whereby respondents with the condition of interest (foot pain) were more likely to respond.

The high prevalence of foot pain, comorbidity and multi-morbidity in this sample may also be explained by the student recruitment profile of GCU and the demographic characteristics of its students. One of GCU's main goals is to widen access to higher education and $17 \%$ of new entrants in 2017 were from the lowest quintile of social deprivation, higher than the sector average of $10 \%$ [52]. At the GCU Glasgow campus more than 70\% of students come from Greater Glasgow or the West of Scotland and around 10\% are from the most deprived areas in Scotland. The socioeconomic composition of Glasgow differs to that of the rest of Scotland and the UK, with higher levels of deprivation, poor health behaviours, disease, suicide and lower life expectancy [53-55]. Interestingly, at the time of the survey respondents were largely from upper 6 deciles (more affluent) for social deprivation, and predominantly employed in high-level managerial or professional occupations. However, a major limitation of using current measures of social deprivation is that they do not necessarily account for cumulative exposures to social deprivation experienced earlier in life [56].

A strength of the current survey is that the correlates of foot pain identified appear to be largely theoretically consistent with findings from other large-scale population surveys $[3,4]$. Foot pain and foot health characteristics were generally worse amongst females, with female gender associated with greater prevalence of pain affecting heel, forefoot and ball of the foot [3, 4, 57]. Moreover, presence of superficial foot problems such as callous, corns and nails problems, as well as structural problems such as bunions were associated with female gender, whilst the presence of fungal infections was associated with male gender [4]. Similar findings have been previously attributed to relatively poor footwear habits adopted by women compared to men $[3,6]$. Future analyses will seek to evaluate the role of past and current footwear habits on foot pain and foot health characteristics in this sample.

This study is in agreement with previous studies in that poorer foot health, footwear-related foot health and HRQoL were all significantly associated with increasing age $[8,58]$. A somewhat surprising finding was that age was not significantly associated with foot pain severity. Less than $5 \%$ of respondents were over the age of 65 , 
Table 4 Regional foot pain characteristics and gender associations

\begin{tabular}{|c|c|c|c|c|}
\hline & Women $(n=399)$ & Men $(n=192)$ & Total $(n=593)^{\mathrm{a}}$ & Odds ratio $(95 \%$ Cl) F:M \\
\hline Moderate-to-severe foot pain, n (\%) & $169(42.4)$ & $66(34.4)$ & $236(39.8)$ & $1.40(0.98-2.01)$ \\
\hline \multicolumn{5}{|l|}{ Foot pain region, n (\%) } \\
\hline Hindfoot & $47(11.8)$ & $26(13.5)$ & $74(12.5)$ & $0.73(0.45-1.18)$ \\
\hline Unilateral & $24(6.0)$ & $16(8.3)$ & $40(6.7)$ & \\
\hline Bilateral & $23(5.8)$ & $10(5.2)$ & $34(5.7)$ & \\
\hline Forefoot & $82(20.6)$ & $37(19.2)$ & $119(20.1)$ & $2.24(1.41-3.56) *$ \\
\hline Unilateral & $45(11.3)$ & $26(13.5)$ & $71(11.9)$ & \\
\hline Bilateral & $37(9.3)$ & $11(5.7)$ & $48(8.1)$ & \\
\hline Toes & $89(22.3)$ & $34(18.7)$ & $123(20.7)$ & $1.42(0.94-2.15)$ \\
\hline Unilateral & $45(11.3)$ & $21(11.9)$ & $66(11.1)$ & \\
\hline Bilateral & $44(11.0)$ & $13(6.8)$ & $57(9.6)$ & \\
\hline Ball & $102(25.6)$ & $43(22.4)$ & $146(24.6)$ & $1.87(1.24-2.81) *$ \\
\hline Unilateral & $41(10.3)$ & $10(5.2)$ & $51(8.6)$ & \\
\hline Bilateral & $61(15.3)$ & $33(17.2)$ & $95(16.0)$ & \\
\hline Arch & $105(26.3)$ & $51(26.6)$ & $156(26.3)$ & $1.09(0.74-1.56)$ \\
\hline Unilateral & $40(10.0)$ & $23(12.0)$ & $63(10.6)$ & \\
\hline Bilateral & 65 (16.3) & $28(14.6)$ & $93(15.7)$ & \\
\hline Heel & $72(18.1)$ & 37 (19.3) & $110(18.5)$ & $1.58(1.01-2.47) *$ \\
\hline Unilateral & $31(7.8)$ & $17(8.9)$ & $49(8.3)$ & \\
\hline Bilateral & $41(10.3)$ & $20(10.4)$ & $61(10.3)$ & \\
\hline Nails & $52(13)$ & $18(9.4)$ & $71(12.0)$ & $1.43(0.83-2.46)$ \\
\hline Unilateral & $28(7.0)$ & $9(4.7)$ & $37(6.2)$ & \\
\hline Bilateral & $24(6.0)$ & $9(4.7)$ & $34(5.7)$ & \\
\hline
\end{tabular}

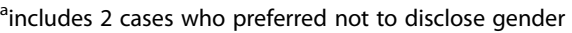

*Pearson's chi square significant at $p<0.05$

Table 5 Foot pathologies and associations with moderate-to-severe foot pain (MSFP)

\begin{tabular}{llllll}
\hline & $\begin{array}{l}\text { Women } \\
(n=399)\end{array}$ & $\begin{array}{l}\text { Men } \\
(n=192)\end{array}$ & $\begin{array}{l}\text { Odds ratio } \\
(95 \% \text { Cl) F:M }\end{array}$ & $\begin{array}{l}\text { Total } \\
(n=593)^{\mathrm{a}}\end{array}$ & $\begin{array}{l}\text { Odds ratio (95\% Cl) MSFP } \\
\text { Vs. no MSFP }\end{array}$ \\
\hline $\begin{array}{l}\text { Female gender, } \mathrm{n}(\%) \\
\begin{array}{l}\text { Foot problems previous } \\
6 \text { months }\end{array}\end{array}$ & - & - & & $399(67.5)$ & $1.40(0.98-2.01)^{*}$ \\
$\quad$ Callous & $183(45.9)$ & $68(35.4)$ & $1.55(1.08-2.20)^{* *}$ & $252(42.5)$ & $1.18(0.73-1.89)$ \\
Corns & $68(17.0)$ & $13(6.8)$ & $2.83(1.52-5.26)^{* *}$ & $81(13.7)$ & $1.18(0.73-1.89)$ \\
Fungal & $58(14.5)$ & $46(24.0)$ & $0.54(0.35-0.83)^{* *}$ & $105(17.5)$ & $1.03(0.67-1.59)$ \\
Verruca & $27(6.8)$ & $7(3.6)$ & $1.92(0.82-4.49)$ & $34(5.7)$ & $1.21(0.60-2.43)$ \\
Bunions & $72(18.0)$ & $3(1.6)$ & $13.87(4.31-44.64)^{* * \mathrm{~b}}$ & $75(12.6)$ & $1.66(1.02-2.69)^{* *}$ \\
Claw toes & $36(9.0)$ & $15(7.8)$ & $1.17(0.62-2.19)$ & $51(8.6)$ & $1.51(0.85-2.68)^{*}$ \\
Nails & $128(32.1)$ & $58(30.2)$ & $1.09(0.75-1.58)$ & $187(31.5)$ & $1.36(0.96-1.91)^{*}$ \\
\hline
\end{tabular}

includes 2 cases who preferred not to disclose gender

${ }^{\mathrm{b}}$ Fisher's exact test

*significant at $p<0.2$

${ }^{* *}$ significant at $p<0.05$ 
Table 6 Comorbidities, health characteristics and associations with moderate-to-severe foot pain (MSFP)

\begin{tabular}{|c|c|c|c|c|}
\hline & $\begin{array}{l}\text { Women } \\
(n=399)\end{array}$ & $\begin{array}{l}\text { Men } \\
(n=192)\end{array}$ & $\begin{array}{l}\text { Total } \\
(n=593)^{c}\end{array}$ & $\begin{array}{l}\text { Odds ratio } \\
\text { (95\% Cl) } \\
\text { MSFP vs. no MSFP }\end{array}$ \\
\hline Heart disease & $4(1.0)$ & $7(3.6)$ & $11(1.9)$ & $0.56(0.15-2.14)$ \\
\hline Treatment & $4(1.0)$ & $5(2.6)$ & $9(1.5)$ & \\
\hline Limiting & $3(0.8)$ & $0(0.0)$ & $3(0.5)$ & \\
\hline High BP & $36(9.0)$ & $22(11.5)$ & $58(9.8)$ & $1.85(1.07-3.18) * *$ \\
\hline Treatment & $32(8.0)$ & $17(8.9)$ & $49(8.3)$ & \\
\hline Limiting & $2(0.5)$ & $2(1.0)$ & $4(0.7)$ & \\
\hline Lung Disease & $12(3.0)$ & $4(2.1)$ & $16(2.7)$ & $0.91(0.33-2.5)$ \\
\hline Treatment & $12(3.0)$ & $3(1.6)$ & $15(2.5)$ & \\
\hline Limiting & $7(1.8)$ & $2(1.0)$ & $9(1.5)$ & \\
\hline Diabetes & $8(2.0)$ & $13(6.8)$ & $21(3.5)$ & $0.75(0.29-1.88$ \\
\hline Treatment & $6(1.5)$ & $9(4.7)$ & $15(2.5)$ & \\
\hline Limiting & $0(0.0)$ & $1(0.5)$ & $1(0.2)$ & \\
\hline Ulcer/stomach & $10(2.5)$ & $7(3.6)$ & $17(2.9)$ & $2.21(0.83-5.89) *$ \\
\hline Treatment & $10(2.5)$ & $5(2.6)$ & $15(2.5)$ & \\
\hline Limiting & $2(0.5)$ & $1(0.5)$ & $3(0.5)$ & \\
\hline Kidney disease ${ }^{d}$ & $2(0.5)$ & $3(1.6)$ & $5(0.8)$ & $2.29(0.38-13.78)$ \\
\hline Treatment & $1(0.3)$ & $1(0.5)$ & $2(0.3)$ & \\
\hline Limiting & $0(0.0)$ & $1(0.5)$ & $1(0.2)$ & \\
\hline Liver disease & $0(0.0)$ & $0(0.0)$ & $0(0.0)$ & - \\
\hline Treatment & $0(0.0)$ & $0(0.0)$ & $0(0.0)$ & \\
\hline Limiting & $0(0.0)$ & $0(0.0)$ & $0(0.0)$ & \\
\hline Anaemia/blood & $17(4.3)$ & $2(1.0)$ & $19(3.2)$ & $1.71(0.69-4.28)$ \\
\hline Treatment & $14(3.5)$ & $2(1.0)$ & $16(2.7)$ & \\
\hline Limiting & $2(0.5)$ & $0(0.0)$ & $0(0.0)$ & \\
\hline Cancer $^{d}$ & $3(0.8)$ & $2(1.0)$ & $5(0.8)$ & $2.29(0.38-13.78)$ \\
\hline Treatment & $3(0.8)$ & $1(0.5)$ & $4(0.7)$ & \\
\hline Limiting & $1(0.3)$ & $0(0.0)$ & $0(0.0)$ & \\
\hline Depression & $50(12.5)$ & $17(8.9)$ & $67(11.2)$ & $1.54(0.93-2.57) *$ \\
\hline Treatment & $41(10.3)$ & $10(5.2)$ & $51(8.6)$ & \\
\hline Limiting & $25(6.3)$ & $7(3.6)$ & $22(3.7)$ & \\
\hline Osteoarthritis & $30(7.5)$ & $3(1.6)$ & $33(5.6)$ & $1.88(0.93-3.81) *$ \\
\hline Treatment & $14(3.5)$ & $1(0.5)$ & $15(2.5)$ & \\
\hline Limiting & $19(4.8)$ & $3(1.6)$ & $22(3.7)$ & \\
\hline Back pain & $114(28.6)$ & $42(21.9)$ & $156(26.3)$ & $2.04(1.41-2.95) * *$ \\
\hline Treatment & $34(8.5)$ & $17(8.9)$ & $51(8.6)$ & \\
\hline Limiting & $43(10.8)$ & $14(7.3)$ & $57(9.6)$ & \\
\hline Rheumatoid arthritis ${ }^{d}$ & $5(1.3)$ & $4(2.1)$ & $9(1.5)$ & $12.49(1.55-100.54) * *$ \\
\hline Treatment & $5(1.3)$ & $2(1.0)$ & $7(1.2)$ & \\
\hline Limiting & $1(0.3)$ & $3(1.6)$ & $4(0.7)$ & \\
\hline Hip pain & $61(15.3)$ & $9(4.70)$ & $70(11.8)$ & $2.72(1.63-4.55) * *$ \\
\hline Treatment & $17(4.3)$ & $3(1.6)$ & $20(3.4)$ & \\
\hline Limiting & $28(7.0)$ & $3(1.6)$ & $31(5.2)$ & \\
\hline Knee pain & $101(25.3)$ & $36(18.8)$ & $137(23.1)$ & $1.56(1.06-2.30) * *$ \\
\hline
\end{tabular}


Table 6 Comorbidities, health characteristics and associations with moderate-to-severe foot pain (MSFP) (Continued)

\begin{tabular}{|c|c|c|c|c|}
\hline & $\begin{array}{l}\text { Women } \\
(n=399)\end{array}$ & $\begin{array}{l}\text { Men } \\
(n=192)\end{array}$ & $\begin{array}{l}\text { Total } \\
(n=593)^{c}\end{array}$ & $\begin{array}{l}\text { Odds ratio } \\
(95 \% \mathrm{Cl}) \\
\text { MSFP vs. no MSFP }\end{array}$ \\
\hline Treatment & $30(7.5)$ & $9(4.7)$ & $39(6.6)$ & \\
\hline Limiting & $54(13.5)$ & $19(9.9)$ & $73(12.3)$ & \\
\hline Other & $76(19.0)$ & $39(20.3)$ & $115(19.4)$ & $1.50(0.99-2.27) *$ \\
\hline Treatment & $38(9.5)$ & $18(9.4)$ & $56(9.4)$ & \\
\hline Limiting & $15(3.8)$ & $15(7.8)$ & $30(5.1)$ & \\
\hline SCQ total, median (IQR) & $1(0-3)$ & $1(0-3)$ & $1(0-3)$ & - \\
\hline$\geq 1$ Medical condition & $226(56.6)$ & $101(52.6)$ & $327(55.1)$ & $1.94(1.38-2.72) * *$ \\
\hline$\geq 2$ Medical conditions (multi-morbidity) & $110(27.6)$ & $50(26.0)$ & $160(26.9)$ & $2.04(1.42-2.95) * *$ \\
\hline Overweight ${ }^{a}$ & $193(52.7)$ & $122(63.5)$ & $316(56.0)$ & $2.01(1.41-2.88) * *$ \\
\hline Low physical activity ${ }^{\text {b }}$ & $45(11.3)$ & $18(9.4)$ & $64(12.5)$ & $0.93(0.54-1.58)$ \\
\hline Current smoker & $19(4.8)$ & $13(6.8)$ & $32(5.4)$ & $0.90(0.43-1.88)$ \\
\hline
\end{tabular}

${ }^{a} n=47$ values missing

${ }^{\mathrm{b}} n=82$ values missing

cincludes 2 cases who preferred not to disclose gender

'Fisher's exact test conducted where cell frequencies $<5$

*significant at $p<0.2$

${ }^{* *}$ significant at $p<0.05$

and of those $44 \%$ had moderate-to-severe foot pain. Whilst this prevalence estimate is higher than has been reported previously for the over 65 age range in other studies [3, 4]; foot pain prevalence was generally high across all age groups with a u-shaped distribution ranging from 30 to $44 \%$, instead of increasing linearly with age. Given the nature of the sampling frame targeting alumni of a young university, a proportional representation of $<5 \%$ within the sample in the over 65 years' age category was not an unexpected finding and therefore these findings do not appear to be due to under-representation of this age group.

Multivariate analyses identified that female gender, obesity, bunions, hip pain, back pain and lower occupational class were significantly and independently associated with moderate-to-severe foot pain. These findings are consistent with previous studies [3, 4, 14]. Obesity has been identified as a significant predictor of non-specific

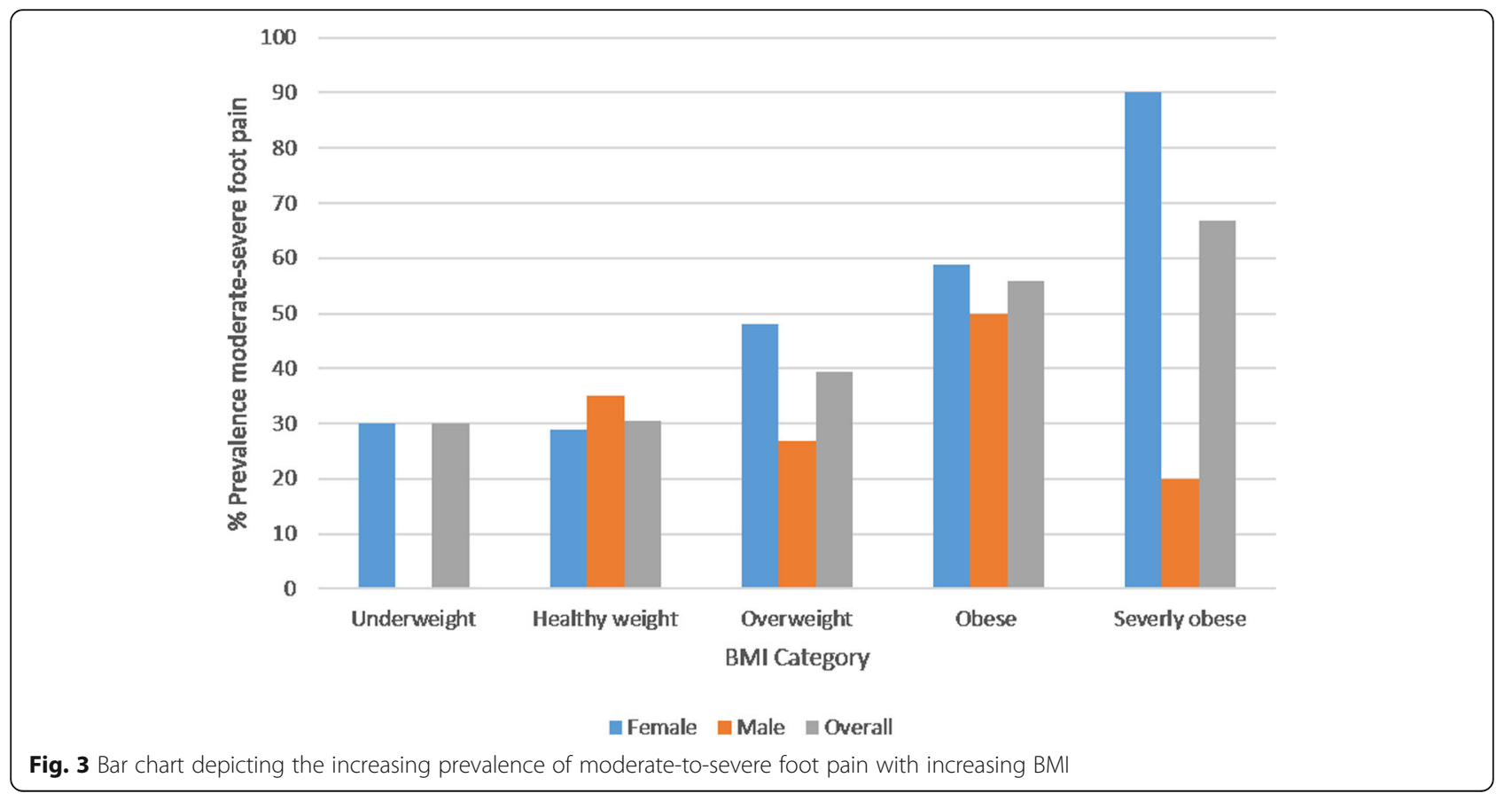


Table 7 Multivariate logistic regression model for independent associations between independent variables and moderate-tosevere foot pain

\begin{tabular}{llllll}
\hline Variable & B & SE & Wald & $p$-value & OR $(95 \% \mathrm{Cl})$ \\
\hline Bunions & 0.63 & 0.28 & 5.25 & $0.022^{*}$ & $1.88(1.09-3.21)$ \\
Back pain & 0.64 & 0.21 & 9.22 & $0.002^{*}$ & $1.90(1.26-2.88)$ \\
RA & 1.74 & 1.11 & 2.44 & 0.118 & $5.67(0.64-50.02)$ \\
Hip Pain & 0.68 & 0.31 & 4.96 & $0.026^{*}$ & $1.97(1.09-3.59)$ \\
BMl Overweight & 0.61 & 0.19 & 10.06 & $0.002^{*}$ & $1.84(1.26-2.68)$ \\
Occupation Class & 0.45 & 0.21 & 4.53 & $0.033^{*}$ & $1.57(1.04-2.37)$ \\
Constant & -1.279 & 0.18 & 52.70 & $0.000^{*}$ & \\
Model performance & & & $x^{2}, \mathrm{df}$ & & \\
Hosmer Lemeshow & - & - & $6.46,6$ & 0.373 & - \\
\hline
\end{tabular}

$N=530$ included in multivariate model

foot pain in several studies and has been linked to increased stresses applied to the foot and metabolic pathways [59-63]. Recent research has demonstrated that weight loss (via bariatric surgery) results in reductions in foot pain severity, suggesting that weight-loss strategies may be a credible therapeutic option for managing foot pain [64]. The role of physical activity in weight-loss strategies to improve health has been well established [65]. However, adherence to weight-loss strategies particularly in the presence of pain is difficult for many people and strategies to promote maintenance of physical activity can be challenging to implement [66]. Brief interventions for physical activity delivered in patient consultation have received attention recently but little evidence is available for their long-term effectiveness $[67,68]$.

The presence of self-reported bunions was associated with moderate-to-severe pain, and was significantly more prevalent in women, which was in agreement with previous studies [69-71]. The term "bunion" is a lay term often used by members of the general public to describe a medial swelling affecting the first metatarsophalangeal joint. We acknowledge that this term not necessarily interchangeable or synonymous with

Table 8 Multivariate linear regression models for associations between moderate-to-severe-foot pain, foot function, foot health and $\mathrm{HRQOL}$

\begin{tabular}{|c|c|c|}
\hline & No MSFP & Yes MSFP \\
\hline 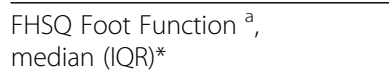 & $100(93.75-100)$ & $87.5(68.75-93.75)$ \\
\hline $\begin{array}{l}\text { FHSQ General Foot Health }{ }^{a} \text {, } \\
\text { median }(\mathrm{IQR})^{*}\end{array}$ & $85(60-85)$ & $60(25-72)$ \\
\hline EQ 5D-5 L Index ${ }^{b}$, median (IQR) ${ }^{*}$ & $84(75-90)$ & $76(60-87)$ \\
\hline EQ 5D-5 L VAS ${ }^{c}$, median (IQR)* & $0.85(0.768-1.00)$ & $0.767(0.697-0.837)$ \\
\hline
\end{tabular}

"hallux valgus" which is characterised by abnormal rotation and lateral deviation of the big toe and as such these results should be interpreted with caution. The lay-friendly term "bunion" was included in the survey to allow self-report of big toe pathology which may or may not have been a true hallux valgus if assessed via clinical examination. This was supplemented with generation of an additional survey item for self-assessment of hallux valgus severity [46] which was graded as at least mild in 72 of 75 respondents who self-reported bunions. With cautious interpretation, the prevalence of self-reported bunions was comparable to other population studies reporting hallux valgus prevalence and has been associated with impaired function, reduced HRQoL and an increased risk of falls in older adults [72]. Conservative management of hallux valgus is predominantly aimed at reducing the need for or delaying surgical intervention, and involves use of foot orthoses, rocker-sole footwear and/or physical therapies to improve first ray function and reduce pain [73, 74]. Known risk factors for hallux valgus are mostly non-modifiable such as female gender and foot structure (i.e. dorsiflexed first metatarsal), however high BMI and poor footwear habits have been identified as modifiable risk factors [70]. Recent evidence suggests that improvements in footwear habits and outcomes related to foot pain and foot function in women aged 50 or over can be achieved with standardised advice on proper shoe characteristics and fit $[75,76]$. It is unclear whether similar outcomes could be replicated in a younger cohort of women who may have different footwear preferences [77, 78].

Back pain and hip pain were independently associated with moderate-to-severe foot pain and this finding is in agreement with a large body of evidence demonstrating strong associations between foot pain and other regional bodily pain $[3,4,37]$. Multi-site joint problems have been identified as common and are associated with increasing age, the presence of comorbidities and social deprivation $[37,79]$. Recent evidence suggests that multi-site joint pain prevalence is increasing and that more holistic management strategies are required whereby health professionals consider joint pain beyond the primary site [79]. This might provide an implementation challenge for podiatrists who are trained in the assessment and management of lower limb complaints, and further referrals to other health professionals such as physiotherapists might add to patients' treatment burden in the context of multimorbidity [18].

Non-professional occupation class was independently associated with of moderate-to-severe foot pain. This confirms the findings from previous research suggesting that a lower class of occupation, which include manual occupations, is a known risk factor for pain and disability [12, $14,15]$. This was an interesting finding given that social 
deprivation measured via indices of social deprivation was not found to be associated with foot pain. Use of occupation class as a proxy measure of socioeconomic status is advantageous as it is associated with other social determinants of health including social status, level of income and level of education attainment [80]. Recent research has shown that a life-course of consistently low socioeconomic position results in a significantly greater odds of reporting chronic disabling pain [81]. Given that this sample all achieved a university level education, it is possible that occupation class is a more useful indicator of cumulative socioeconomic status in this cross-sectional study context than area-based indices of social deprivation, which are vulnerable to the ecological fallacy [80]. These results suggest that while a high level of education attainment may not be protective against moderate-to-severe foot pain, a higher level of occupation class may be. It is possible that this is due to the greater physical demand associated with lower class occupations [15].

There are some limitations to this study that warrant further attention. The response rate was lower than anticipated and little information was available to allow non-responders analyses and so was vulnerable to non-response bias. A small incentive ( $£ 100$ prize draw entry) was offered to participants to boost recruitment rates but this may have resulted in a reduction in data quality, whereby respondents increased satisficing behaviours such as item skipping, rushing, and straightlining (the act of selecting the same response over and over again for fast completion of a survey) $[82,83]$. The survey was administered and completed electronically and required invitees to have an up to date and working email address. This may have resulted in selection bias since not all of the target population would have been able to receive the survey invitation [84]. The sampling frame restricting eligibility to alumni from a single university in Glasgow, with its known health issues, limits the ability to generalizability the survey findings to other university educated populations in the UK. Given the focus on a pre-specified subgroup, these results are not generalizable to the general population. However previous alumni studies such as the Harvard Alumni Study [85] have highlighted that narrow eligibility criteria can be advantageous in terms of convenience for recruiting large samples and achieving statistical power for analyses of group with specific demographic characteristics (such as education level attainment). The survey was cross-sectional in nature and therefore do not reflect causality nor patterns of foot pain and health status beyond a single discrete point in time. Lastly, responses in relation to foot problems and pathologies were by self-report, which may have resulted in some measurement error due to lack of prior knowledge about these conditions amongst respondents.

\section{Conclusions}

Moderate-to-severe foot pain was highly prevalent in a university-educated population and was independently associated with female gender, bunions, obesity, back pain, hip pain and lower occupational class. Respondents with moderate-to-severe foot pain had significantly worse scores for foot function, foot health and HRQoL. Education attainment does not appear to be protective against moderate-to-severe foot pain.

\section{Abbreviations \\ BMI: Body mass index; BP: Blood pressure; Cl: Confidence interval; EQ 5D-5 L: Euro quality of life (Euroqol) five dimension 5 level questionnaire; FHSQ: Foot health status questionnaire; GCU: Glasgow Caledonian University; HRQoL: Health-related quality of life; IPAQ-SF: International physical activity questionnaire short form; IQR: Inter-quartile range; OA: Osteoarthritis; OR: Odds ratio; RA: Rheumatoid arthritis; REDCap: Research Electronic Data Capture; SCQ: Self-assessment comorbidity questionnaire; UK: United Kingdom; VAS: Visual analogue scale}

\section{Acknowledgements}

The authors thank the GCU Alumni Office and Mr. John Taylor for facilitating administration of the survey.

\section{Funding}

For the purposes of providing a small incentive to participate, the School of Health and Life Sciences, Glasgow Caledonian University funded two separate prizes of $£ 100$ vouchers for an online retailer. Winners were selected at random via prize draw.

\section{Availability of data and materials}

Datasets are available from the corresponding author upon reasonable request.

\section{Authors' contributions}

All authors contributed to the study conception and design. GJH identified the study sample. LF constructed the survey instrument. GJH conducted all data collection and takes responsibility for the integrity of the data and data analysis. All authors contributed to data analyses, interpretation of the data and intellectual content of the manuscript and approved the final submission.

Ethics approval and consent to participate

Research ethics committee approval was obtained from the Glasgow Caledonian University School of Health and Life Sciences Research Ethics

Committee (HLS/PSWAHP/17/152) and written informed consent was obtained from all respondents.

Consent for publication

Not applicable.

\section{Competing interests}

The authors declare that they have no competing interests.

\section{Publisher's Note}

Springer Nature remains neutral with regard to jurisdictional claims in published maps and institutional affiliations.

Received: 19 July 2018 Accepted: 9 August 2018

Published online: 17 August 2018

References

1. Gill TK, Menz HB, Landorf KB, Arnold JB, Taylor AW, Hill CL. Predictors of foot pain in the community: the North West Adelaide health study. J Foot Ankle Res. 2016;9:23. 
2. Thomas MJ, Roddy E, Zhang W, Menz HB, Hannan MT, Peat GM. The population prevalence of foot and ankle pain in middle and old age: a systematic review. Pain. 2011;152:2870-80.

3. Hill CL, Gill TK, Menz HB, Taylor AW. Prevalence and correlates of foot pain in a population-based study: the North West Adelaide health study. J Foot Ankle Res. 2008;1:2.

4. Garrow AP, Silman AJ, MacFarlane GJ. The Cheshire foot pain and disability survey: a population survey assessing prevalence and associations. Pain. 2004;110:378-84.

5. Walsh TP, Butterworth PA, Urquhart DM, Cicuttini FM, Landorf KB, Wluka AE, Shanahan M, Menz HB. Increase in body weight over a two-year period is associated with an increase in midfoot pressure and foot pain. J Foot Ankle Res. 2017:10:31.

6. Dufour AB, Broe KE, Nguyen UDT, Gagnon DR, Hillstrom HJ, Walker AH, Kivell E, Hannan MT. Foot pain: is current or past Shoewear a factor? The Framingham Foot Study. Arthritis Rheum. 2009;61(10):1352-8.

7. Cotchett MP, Whittaker G, Erbas B. Psychological variables associated with foot function and foot pain in patients with plantar heel pain. Clin Rheumatol. 2015; 34:957-64.

8. Mickle KJ, Munro BJ, Lord SR, Menz HB, Steele JR. Cross-sectional analysis of foot function, functional ability, and health related quality of life in older people with disabling foot pain. Arthritis Care Res. 2011;63(11):1592-8.

9. Katsambas A, Abeck D, van de Kerkhof P, Burzykowski T, Molenberghs $G$ Marynissen $\mathrm{G}$. The effects of foot disease on quality of life: results of the Achilles project. JEADV. 2005;19:191-5.

10. Menz HB, Jordan KP, Roddy E, Croft PR. Characteristics of primary care consultations for musculoskeletal foot and ankle problems in the UK. Rheumatology. 2010;49(7):1391-8.

11. Butterworth PA, Landorf KB, Gilleard W, Urquhart DM, Menz HB. The association between body composition and foot structure and function: a systematic review. Obes Rev. 2014;15(4):348-57.

12. Chatterton BD, Muller S, Roddy E. Epidemiology of posterior heel pain in the general population: cross-sectional findings from the clinical assessment study of the foot. Arthritis Care Res. 2015;67(7):996-1003.

13. Urwin M, Symmons D, Allison T, Brammah T, Busby H, Roxby M, Simmons A, Williams G. Ann Rheum Dis. 1998;57:649-55.

14. Thomas MJ, Peat G, Rathod T, Marshall M, Moore A, Menz HB, Roddy E. The epidemiology of symptomatic midfoot $\mathrm{OA}$ in community-dwelling older adults: cross-sectional findings from the Clinical Assessment Study of the Foot. Arthritis Res Ther. 2015;17:178.

15. Menz HB, Roddy E, Marshall M, Thomas MJ, Rathod T, Myers H, Thomas E, Peat GM. Demographic and clinical factors associated with radiographic severity of first metatarsophalangeal joint OA: crosssectional findings from the clinical assessment study of the foot. Osteoarthr Cartil. 2015;23(1):77-82.

16. Bergin SM, Munteanu SE, Zammit GV, Nikolopoulos N, Menz HB. Impact of first metatarsophalangeal joint OA on health-related quality of life. Arthritis Care Res. 2012;64(11):1691-8.

17. Barnett K, Mercer SW, Norbury M, Watt G, Wyke S, Guthrie B. Epidemiology of multimorbidity and implications for health care, research, and medical education: a cross-sectional study. Lancet. 2012;380:37-43.

18. Mair FS, May CR. Thinking about the burden of treatment. BMJ. 2014;349:96680

19. May CR, Eton DT, Boehmer K, Gallacher K, Hunt KJ, MacDonald S, et al. Rethinking the patient: using burden of treatment theory to understand the changing dynamics of illness. BMC Health Serv Res. 2014;14:281.

20. Lowe DB, Taylor MJ, Hill SJ. Associations between multimorbidity and additional burden for working-age adults with specific forms of musculoskeletal conditions: a cross-sectional study. BMC Musculoskelet Disord. 2017;18:135.

21. Sav A, King MA, Whitty JA, Kendall E, McMillan SS, Kelly F, et al. Burden of treatment for chronic illness: a concept analysis and review of the literature. Health Expect. 2013;15:351-9.

22. Davies J, Sullivan S, Zammit S. Adverse life outcomes associated with adolescent psychotic experiences and depressive symptoms. Soc Psychiatry Psychiatr Epidemiol. 2018;53(5):497-507.

23. Ross $C E$, Wu CL. Education, age, and the cumulative advantage in health. $J$ Health Soc Behav. 1996;37(1):104-20.

24. Viner RM, Ozer EM, Denny S, Marmot M, Resnick M, Fatusi A, Currie C. Adolescence and the social determinants of health. Lancet. 2012;379(9826): $1641-52$.
25. Munteanu SE, Zammit GV, Menz HB. Factors associated with foot pain severity and foot-related disability in individuals with first metatarsophalangeal joint OA. Rheumatology. 2012;51:176-83.

26. Harris PA, Taylor R, Thielke R, Payne J, Gonzalez N, Conde JG. Research electronic data capture (REDCap) - a metadata-driven methodology and workflow process for providing translational research informatics support. J Biomed Inform. 2009;42(2):377-81.

27. Times Higher Education Young University Rankings: https:/www. timeshighereducation.com/world-university-rankings/2017/younguniversityrankings\#!/page/0/length/25/sort_by/rank/sort_order/asc/cols/ stats. Accessed July 2018.

28. Survey Monkey Sample Size Calculator: https://www.surveymonkey.com/ mp/sample-size-calculator/. Accessed July 2018.

29. Draugalis JR, Plaza CM. Best Practices for Survey Research Reports Revisited: Implications of Target Population, Probability Sampling, and Response Rate. Am J Pharm Educ. 2009;73(8):142.

30. NHS UK: What is the body mass index (BMI)?: https://www.nhs.uk/chq/ Pages/3215.aspx?Category|D=51\&SubCategorylD=165. Accessed July 2018.

31. Wikipedia: Classification of ethnicity in the United Kingdom: https://en. wikipedia.org/wiki/Classification_of_ethnicity_in_the_United_Kingdom\#cite_ note-Onsethngr-29. Accessed July 2018.

32. Office for National Statistics. Standard Occupation Classification (SOC): https://www.ons.gov.uk/methodology/classificationsandstandards/ standardoccupationalclassificationsoc. Accessed July 2018.

33. Scottish Government. The Scottish Index of Multiple Deprivation: http:// www.gov.scot/Topics/Statistics/SIMD. Accessed July 2018.

34. UK Government. English indices of deprivation 2015: https:/www.gov.uk/ government/statistics/english-indices-of-deprivation-2015. Accessed July 2018.

35. UK Data Service Census Support. Geoconvert: http://geoconvert.mimas.ac. ukJ. Accessed July 2018.

36. Sangha O, Stucki G, Liang MH, Fossel AH, Katz JN. Arthritis Rheum. 2003; 49(2):156-63.

37. Keenan AM, Tennant A, Fear J, Emery P, Conaghan PG. Impact of multiple joint problems on daily living tasks in people in the community over age fifty-five. Arthritis Rheum. 2006;55(5):757-64.

38. Herdman M, Gudex C, Lloyd A, Janssen MF, Kind P, Parkin D, Bonsel G, Badia X. Development and preliminary testing of the new five-level version of EQ-5D (EQ-5D-5L). Qual Life Res. 2011:20(10):1727-36.

39. Janssen MF, Pickard AS, Golicki D, Gudex C, Niewada M, Scalone L, Swinburn P, Busschbach J. Measurement properties of the EQ-5D-5L compared to the EQ-5D-3L across eight patient groups: a multi-country study. Qual Life Res. 2013;22(7):1717-27.

40. Dawson J, Boller I, Doll H, Lavis G, Sharp R, Cooke P, Jenkinson C. Responsiveness of the Manchester-Oxford foot questionnaire (MOXFQ) compared with AOFAS, SF-36 and EQ-5D assessments following foot or ankle surgery. Bone Joint J. 2012;94B(2):215-21.

41. Lee PH, MacFarlane DJ, Lam TH, Stewart SM. Validity of the international physical activity questionnaire short form (IPAQ-SF): A systematic review. Int J Behav Nutr Phys Act. 2011:8:115.

42. Craig $C L$, Marshall AL, Sjorstrom M, Bauman AE, Booth ML, Ainsworth BE, Pratt M, Ekelund U, Yngve A, Sallis JF, Oja P. International physical activity questionnaire: 12-country reliability and validity. Med Sci Sports Exerc. 2003; 35(8):1381-95.

43. Grimm EK, Swartz AM, Hart T, Miller NE, Strath SJ. Comparison of the IPAQshort form and Accelerometry predictions of physical activity in older adults. J Aging Phys Act. 2012;20(1):64-79.

44. Hannan MT, McLennan CE, Rivinus MC, et al. Population-based study of foot disorders in men and women from the Framingham study. Arthritis Rheum. 2006;54(suppl):S497.

45. Collins SL, Moore RA, McQuay HJ. The visual analogue pain intensity scale: what is moderate pain in millimetres? Pain. 1997;72:95-7.

46. Menz HB, Fotoohabadi MR, Wee E, Spink MJ. Validity of self-assessment of hallux valgus using the Manchester scale. BMC Musculoskelet Disord. 2010;1:215.

47. Riskowski JL, Hagedorn TJ, Hannan MT. Measures of Foot Function, Foot Health, and Foot Pain. Arthritis Care Res. 2011;63(S11):S229-39.

48. Bennett PJ, Patterson C, Wearing S, Baglioni T. Development and validation of a questionnaire designed to measure foot-health status. J Am Podiatr Med Assoc. 1998;88(9):419-28.

49. Draugalis JR, Coons SJ, Plaza CM. Best practices for survey research reports: a synopsis for authors and reviewers. Am J Pharm Ed. 2008; 72(1):11. 
50. Office for National Statistics. Graduate in the UK labour market 2017: https:// www.ons.gov.uk/employmentandlabourmarket/peopleinwork/ employmentandemployeetypes/articles/graduatesintheuklabourmarket/ 2017\#steady-increase-in-the-number-of-graduates-in-the-uk-over-the-pastdecade. Accessed July 2018.

51. Duffield SJ, Ellis BM, Goodson N, Walker-Bone K, Conaghan PC, Margham T, Loftis T. The contribution of musculoskeletal disorders in multimorbidity: implications for practice and policy. Best Pract Res Clin Rheumatol. 2017;31: 129-44.

52. Glasgow Caledonian University. Widening Access: https://www.gcu.ac.uk/ theuniversity/wideningaccess/. Accessed July 2017.

53. Martin JL, McLean G, Park J, Martin DJ, Connolly M, Mercer SW, Smith DJ. Impact of socioeconomic deprivation on rate and cause of death in severe mental illness. BMC Psychiatry. 2014;14:261.

54. Gray L, Leyland AH. Is the "Glasgow effect" of cigarette smoking explained by socio-economic status?: a multilevel analysis. BMC Public Health. 2009;9:245.

55. Tunstall-Pedoe H, Kuulasmaa K, Mahonen M, Tolonen H, Ruokokoski E, Amouyel $P$. Contribution of trends in survival and coronary event rates to changes in coronary heart disease mortality: 10-year results from $37 \mathrm{WHO}$ MONICA project populations. Lancet. 1999;353(9164):1547-57.

56. Bauman $\sqcup$, Silver EJ, Stein REK. Cumulative social disadvantage and child health. Pediatrics. 2006;117:1321-8.

57. Benvenuti F, Ferrucci L, Guralnik JM, Gangemi S, Baroni A. Foot pain and disability in older persons: an epidemiologic survey. J Am Geriatr Soc. 1995; 43(5):479-84.

58. Lopez DL, Gonzalez LC, Iglesias MEL, Canosa JLS, Sanz DR, Lobo CC, Vallejo RBB. Quality of life impact related to foot health in a sample of older people with hallux Valgus. Aging Dis. 2016;7(1):45-52.

59. Walsh TP, Gill TK, Evans AM, Yaxley A, Shanahan EM, Hill CL. Association of fat Mass and Adipokines with Foot Pain in a community cohort. Arthritis Care Res. 2016;68(4):526-33.

60. Butterworth PA, Urquhart DM, Landorf KB, Wluka AE, Cicuttini FM, Menz HB. Foot posture, range of motion and plantar pressure characteristics in obese and non-obese individuals. Gait Posture. 2015;41:465-9.

61. Butterworth PA, Menz HB, Urquhart DM, Cicuttini FM, Pasco JA, Brennan SL, Wluka AE, Strauss BJ, Proietto J, Dixon JB, Jones G, Landorf KB. The association between obesity and foot pain: metabolic, biomechanical or both? J Foot Ankle Res. 2015;8(Suppl2):05.

62. Butterworth PA, Landorf KB, Smith SE, Menz HB. The association between body mass index and musculoskeletal foot disorders: a systematic review. Obes Rev. 2012;13:630-42.

63. Tanamas SK, Wluka AE, Berry P, Menz HB, Strauss BJ, Davies-Tuck M, Proeitto J, Dixon JB, Jones G, Cicuttini FM. Relationship between obesity and foot pain and its association with fat mass, fat distribution, and muscle mass. Arthritis Care Res. 2012;64(2):262-8.

64. Walsh TP, Gill TK, Evans AM, Yaxley A, Chisholm JA, Kow L, Arnold JB, Shanahan EM. Changes in foot pain, structure and function following bariatric surgery. J Foot Ankle Res. 2018;11:35.

65. Swift DL, Johannsen NM, Lavie CJ, Earnest CP, Church TS. The role of exercise and physical activity in weight loss and maintenance. Prog Cardiovasc Dis. 2014;56(4):441-7.

66. Lemstra M, Bird Y, Nwankwo C, Rogers M, Moraros J. Weight loss intervention adherence and factors promoting adherence: a meta-analysis. Patient Prefer Adherence. 2016;10:1547-59.

67. Lamming L, Pears S, Mason D, Morton K, Bijker M, Sutton S, Hardemann W, on behalf of the VBI Programme Team. What do we know about brief interventions for physical activity that could be delivered in primary care consultations? A systematic review of reviews. Prev Med. 2017;99:152-63.

68. Vijay GC, Wilson ECF, Suhrcke M, Hardeman W, Sutton, on behalf of the VBI Programme Team. Are brief interventions to increase physical activity cost-effective? A systematic review. Br J Spors Med. 2016;50: 408-17.

69. Menz HB, Roddy E, Thomas E, Croft PR. Impact of hallux Valgus severity on general and foot-specific health-related quality of life. Arthritis Care Res. 2011;63(3):396-404.

70. Nguyen USDT, Hillstrom HJ, Li W, Dufour AB, Kiel DP, Procter-Gray E, Gagnon MM, Hannan MT. Factors associated with hallux valgus in a population-based study of older women and men: the MOBILIZE Boston Study. Osteoarthritis Cartilage. 2010;18:41-6.

71. Roddy R, Zhang W, Doherty M. Prevalence and associations of hallux valgus in a primary care population. OA. 2008;59(6):857-62.
72. Nix S, Smith M, Vicenzino B. Prevalence of hallux valgus in the general population: a systematic review and meta-analysis. J Foot Ankle Res. 2010;3:21.

73. Menz HB, Auhl M, Tan JM, Levinger P, Roddy E, Munteanu SE. Effectiveness of foot orthoses versus rocker-sole footwear for first metatarsophalangeal joint OA: randomized trial. Arthritis Care Res. 2016;68(5):581-9.

74. Zammit GV, Menz HB, Munteanu SE, Landorf KB, Gilheany MF. Interventions for treating $\mathrm{OA}$ of the big toe joint. Cochrane Database Syst Rev. 2010;9:CD007809.

75. van der Zwaard BC, Poppe E, Vanwanseele B, van der Horst HE, Elders PJM. Development and evaluation of a leaflet containing shoe advice: a randomized controlled trial. Fam Pract. 2014;31(3):267-72

76. van der Zwaard BC, van der Horst HE, Knol DL, Vanwanseele B, Elders PJM. Treatment of forefoot problems in older people: a randomized clinical trial comparing podiatric treatment with standardized shoe advice. Ann Fam Med. 2014;12:432-40.

77. Ozdinc S, Unsar S, Kostak MA. Musculoskeletal problems and attitudes towards footwear among university students. J Back Musculoskelet Rehabil. 2018; https://doi.org/10.3233/BMR.

78. Branthwaite H, Chockalingam N, Grogan S, Jones M. Footwear choices made by young women and their potential impact on foot health. J Health Psychol. 2012;18(11):1422-31.

79. Finney A, Dziedzic KS, Lewis M, Healey E. Multisite peripheral joint pain: a cross-sectional study of prevalence and impact on general health, quality of life, pain intensity and consultation behaviour. BMC Musculoskelet Disord. 2017;18:535

80. Marshall IJ, Wang Y, Crichton S, McKevitt C, Rudd AG, Wolfe CDA. The effects of socioeconomic status on stroke risk and outcomes. Lancet Neurol. 2015;14(12):1206-18.

81. Lacey RJ, Belcher J, Croft PR. Does life course socio-economic position influence chronic disabling pain in older adults? A general population study. Eur J Pub Health. 2012;23(4):534-40.

82. Toepoel V. Effects of incentives in surveys. In: Gideon L, editor. Handbook of survey methodology for the social sciences. New York: Springer; 2012. p. 209-23.

83. Barge $\mathrm{S}$, Gehlbach $\mathrm{H}$. Using the theory of satisficing to evaluate the quality of survey data. Res High Educ. 2012;53:182-200.

84. McPeake J, Bateson M, O'Neill A. Electronic surveys: how to maximise success. Nurse Res. 2014;21(3):24-6.

85. Paffenbarger RS, Wing AL, Hyde RT. Physical activity as an index of heart attack risk in college alumni. Am J Epidemiol. 1978;108(3):161-75.

\section{Ready to submit your research? Choose BMC and benefit from:}

- fast, convenient online submission

- thorough peer review by experienced researchers in your field

- rapid publication on acceptance

- support for research data, including large and complex data types

- gold Open Access which fosters wider collaboration and increased citations

- maximum visibility for your research: over $100 \mathrm{M}$ website views per year

At BMC, research is always in progress.

Learn more biomedcentral.com/submissions 